\title{
Reproducibility of a short semi-quantitative food group questionnaire and its performance in estimating nutrient intake compared with a 7-day diet diary in the Million Women Study
}

\author{
Andrew W Roddam ${ }^{1, *}$, Elizabeth Spencer ${ }^{1}$, Emily Banks ${ }^{2}$, Valerie Beral ${ }^{1}$, Gillian Reeves ${ }^{1}$, \\ Paul Appleby ${ }^{1}$, Isobel Barnes ${ }^{3}$, David C Whiteman ${ }^{4}$ and Timothy J Key ${ }^{1}$ \\ ${ }^{1}$ Cancer Research UK Epidemiology Unit, University of Oxford, Radcliffe Infirmary, Oxford OX2 6HE, UK: ${ }^{2}$ National \\ Centre for Epidemiology \& Population Health, Australian National University, Canberra, Australia: ${ }^{3}$ School of \\ Applied Statistics, University of Reading, Reading, UK: ${ }^{4}$ Division of Population Studies and Human Genetics, \\ Queensland Institute of Medical Research, Brisbane, Australia
}

Submitted 6 May 2004: Accepted 21 September 2004

\begin{abstract}
Objectives: To assess the short- and long-term reproducibility of a short food group questionnaire, and to compare its performance for estimating nutrient intakes in comparison with a 7-day diet diary.

Design: Participants for the reproducibility study completed the food group questionnaire at two time points, up to 2 years apart. Participants for the performance study completed both the food group questionnaire and a 7-day diet diary a few months apart. Reproducibility was assessed by kappa statistics and percentage change between the two questionnaires; performance was assessed by kappa statistics, rank correlations and percentages of participants classified into the same and opposite thirds of intake.

Setting: A random sample of participants in the Million Women Study, a populationbased prospective study in the UK.

Subjects: In total, 12221 women aged 50-64 years.

Results: In the reproducibility study, $75 \%$ of the food group items showed at least moderate agreement for all four time-point comparisons. Items showing fair agreement or worse tended to be those where few respondents reported eating them more than once a week, those consumed in small amounts and those relating to types of fat consumed. Compared with the diet diary, the food group questionnaire showed consistently reasonable performance for the nutrients carbohydrate, saturated fat, cholesterol, total sugars, alcohol, fibre, calcium, riboflavin, folate and vitamin C. Conclusions: The short food group questionnaire used in this study has been shown to be reproducible over time and to perform reasonably well for the assessment of a number of dietary nutrients.
\end{abstract}

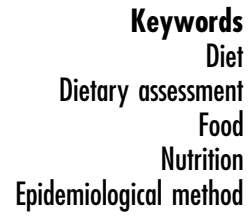

The measurement of average long-term dietary intake in large epidemiological studies is difficult. A balance has to be achieved between methods that have high accuracy and those that are easy in terms of implementation and data capture. In the case of self-reported dietary intake, these two extremes are often characterised by a multi-day diet diary $^{1}$ and a machine-readable food-frequency questionnaire $(F F Q)^{2}$. Numerous reproducibility and validation studies have been reported for these instruments ${ }^{3}$ although it has long been recognised that there are considerable sources of error, both systematic and random, which can markedly affect the results of epidemiological analyses.

For the Million Women Study, which is a prospective cohort study of over one million females in the $\mathrm{UK}^{4}$, a short semi-quantitative food group questionnaire was developed with the main aim of ranking individuals into categories according to intakes of foods and nutrients. This brief questionnaire was designed to capture the main sources of variability in the diets of the target population of UK women aged in their fifties and sixties. It differs from a traditional FFQ in that, instead of asking how often the respondent eats a specific food (e.g. lamb chops, carrots, fish fingers), the food group questionnaire first asks how often she typically eats any food within a particular food group (e.g. meat, fish) and then asks which foods within this group are usually eaten once a week or more often. For foods such as cooked vegetables, salad and fruit, participants were also asked about the quantity of the food group eaten per week (e.g. number of tablespoons of 
cooked vegetables, number of items of fresh fruit). The food group questionnaire asks respondents to write down the estimated number of times, or food items, eaten per week, rather than indicating consumption in pre-defined categories.

The food group questionnaire was designed to gather information on broad dietary groups and extremes of diet, including ascertaining which participants do not eat certain foods such as meat, dairy products or eggs. The questionnaire also asks about some dietary or culinary practices believed to relate to future health, such as use of saturated or unsaturated fats when cooking, addition of salt to food and removal of fat from meat.

The food group questionnaire was developed on the basis of the results from a pilot study of participants completing a 7-day diet diary that sought to establish the main sources of particular nutrients or food components and the sources of variation in intakes. For example, it was found that the main sources of dietary fibre and of variation in fibre intake were bread, breakfast cereals, fruit and vegetables. Questions about these items were therefore included on the food group questionnaire.

An inherent problem in assessing the reproducibility of dietary questionnaires over time is that differences between time points can reflect either real changes in dietary habits (long-term underlying changes or shortterm seasonal changes) or poor repeatability. The aim of the present paper is to assess both the short- and long-term reproducibility of the semi-quantitative food group questionnaire, distinguishing those items which might reflect real dietary changes from those which have poor repeatability. Additionally, the performance of the food group questionnaire for estimating nutrient intakes, comparing results from the questionnaire with those obtained from a 7-day diet diary, was assessed.

\section{Materials and methods}

\section{Study population}

This study was carried out on a subset of women participating in the Million Women Study. The Million Women Study is a population-based, multi-centre prospective study in the UK aiming to investigate the association of hormone replacement therapy and other factors with health, and is described in detail elsewhere ${ }^{4}$. Briefly, recruitment of over one million women aged 50-64 years from the UK general population took place between May 1996 and March 2001. Participants joined by completing a self-administered questionnaire on lifestyle, sociodemographic factors, reproductive factors, past health and use of hormone replacement therapy, which they returned immediately prior to attendance at routine breast screening organised by the National Health Service. A Townsend deprivation score ${ }^{5}$, which is an index of social class derived from each participant's area of residence, based on car and home ownership, overcrowding and employment levels, was allocated to each participant on the basis of their postcode of residence.

Approximately 2-3 years after recruitment into the Million Women Study all women were mailed a selfadministered follow-up questionnaire that updated information on a range of measures, including new questions on diet. Recruitment and follow-up questionnaires can be viewed at http://www.millionwomenstudy.org.

The dietary study population for this analysis comprised a random sample of women recruited into the Million Women Study between January and March 1997. Of the 19795 women sent a follow-up questionnaire, 12221 (response rate 62\%) were returned and these women were divided at random into five groups to be followed for further information on their diet. Four of the five groups (each with approximately 2000 participants) received a second copy of the follow-up questionnaire 3, 6, 12 or 24 months after the initial follow-up questionnaire was completed to assess short-term, seasonal (diets in opposite seasons of the year) and long-term trends in dietary consumption, respectively. Women in the fifth group (approximately 4000 participants) were mailed a 7-day diet diary approximately 3 months after completion of the follow-up questionnaire. In the four groups sent a repeat follow-up questionnaire 5063 questionnaires were returned (response rate 62\%), whilst in the diet diary group 1785 diaries were returned (response rate 44\%).

\section{Food group questionnaire}

The short food group questionnaire comprised 18 questions on the types and frequency of food intakes relating to a typical week; the questionnaire is reproduced in the Appendix.

Completed food group questionnaires were checked and data were entered using operator-verified datacapture software (Eyes \& Hands ${ }^{\circledR}$; ReadSoft Ltd, Milton Keynes, UK). Overall consumption for each food item in a food group was proportionately allocated, using standard portion sizes ${ }^{6}$, according to the amount of each food group the participant reported eating each week. Daily nutrient intakes were calculated using data from McCance E Widdowson's The Composition of Foods and its supplements $^{7-16}$.

\section{7-Day diet diary}

The 7-day diet diary used was identical to the EPICOxford diary ${ }^{17}$ developed for use by the EPIC-Oxford and EPIC-Norfolk arms of the European Prospective Investigation into Cancer and Nutrition (EPIC) study. Participants reported either weighed portions or used photographs of portions provided in the diary when reporting portion sizes. A random sample of 202 of the available 1785 diaries, representative of each geographical recruitment region, was selected and coded using the food-coding program WISP version $2.0^{18}$ to derive estimated daily nutrient intakes. 


\section{Nutrient analysis}

Nutrients included in this analysis were dietary energy, protein, total fat, saturated fat, monounsaturated fat, polyunsaturated fat, dietary cholesterol, carbohydrate, total sugars, alcohol, fibre (non-starch polysaccharides), calcium, retinol, carotene, thiamin, riboflavin, niacin, vitamin $\mathrm{B}_{6}$, folate, vitamin $\mathrm{B}_{12}$, vitamin $\mathrm{C}$, vitamin $\mathrm{D}$ and vitamin E. Dietary supplement data from either the food group questionnaire or the 7-day diet diary were not included.

Nutrients were considered both unadjusted for energy and adjusted for energy using the residual method ${ }^{2}$.

\section{Unreliable intakes}

Ratios of energy intake (EI) to estimated basal metabolic rate $(\mathrm{BMR})^{19}$ were calculated as a measure of the extent of unreliable reporting by both dietary methods. Participants in the top and bottom $2.5 \%$ of the distribution of the ratio $\mathrm{EI} /(\mathrm{BMR} \times 1.4)$ were classified as having unreliable reported intakes.

\section{Statistical analysis}

Before analyses, certain assumptions needed to be made regarding missing values in the food group questionnaire. For the food item (yes/no) questions, if there were no responses in a block of yes/no questions relating to a particular food group (indicating that items were either consumed at least once a week or never consumed), it was assumed that answers to the entire block of questions were missing. For the food intake questions, a blank response on a questionnaire was considered to be a missing value; the robustness of the results to this assumption was assessed by repeating the analysis, recoding a blank on the questionnaire as a zero.

All comparisons were made separately between the baseline food group questionnaire and each of the repeat questionnaires.

For the food item (yes/no) questions, agreement between the baseline and repeat questionnaires was assessed by means of the kappa statistic ${ }^{20}$. Values of kappa over 0.80 indicate excellent agreement, between 0.61 and 0.80 very good agreement, between 0.41 and 0.60 moderate agreement, between 0.21 and 0.40 fair agreement and less than 0.20 poor agreement ${ }^{20}$. For food intake questions, the proportional change in average intake between the baseline and repeat dietary questionnaires was computed.

Nutrient intakes calculated from the 7-day diet diary, the food group questionnaire and percentage differences between the 7-day diet diary and the food group questionnaire were expressed as medians. Differences between absolute nutrient intakes from the 7-day diet diary and the food group questionnaire were assessed using the Kruskal-Wallis test. Pearson rank correlations were used to assess the relative degree of agreement between the 7-day diet diary and the food group questionnaire. Nutrient intakes from both the 7-day diet diary and the food group questionnaire were categorised into tertiles and a weighted kappa was calculated using Fleiss-Cohen weights ${ }^{21}$ which attach greater importance to near disagreements.

All statistical analyses were performed in the data analysis language $\mathrm{R}^{22}$.

\section{Results}

\section{Description of study participants}

Among the 12221 women who were included in the detailed dietary follow-up study, the mean age at recruitment was 56.0 (standard error (SE) 0.03) years and mean body mass index (BMI) was 25.8 (SE 0.03) $\mathrm{kg} \mathrm{m}^{-2}$. There were no significant differences between age at recruitment, BMI or deprivation index in the five groups selected for further dietary follow-up. Those who did not respond to either the repeat food group questionnaire or the 7-day diet diary were on average slightly younger, had higher BMI and were from more deprived areas than those who either responded to both questionnaires or completed a 7-day diet diary (Table 1). The 202 women whose diaries were selected for analysis were on average 1 year older $(P<0.01)$ but had similar BMI and deprivation index compared with those women whose diaries were not selected.

Table 1 Characteristics of respondents in the repeatability and performance study

\begin{tabular}{|c|c|c|c|c|}
\hline & $n(\%)$ & $\begin{array}{c}\text { Age } \\
\text { (years)* }^{\star}\end{array}$ & $\begin{array}{c}\text { Body mass } \\
\text { index }\left(\mathrm{kg} \mathrm{m}^{-2}\right)^{*}\end{array}$ & $\begin{array}{l}\text { Deprivation } \\
\text { index* } †\end{array}$ \\
\hline Overall sample (who returned a follow-up questionnaire) & 12221 & $56.0(0.03)$ & $25.8(0.04)$ & $-1.45(0.03)$ \\
\hline $\begin{array}{l}\text { Returned repeat questionnaire } \\
\text { No reply to repeat questionnaire } \\
P \text {-value for difference }\end{array}$ & $\begin{array}{l}5063(62) \\
3103(38)\end{array}$ & $\begin{array}{l}56.1(0.07) \\
55.9(0.08) \\
\text { NS }\end{array}$ & $\begin{array}{l}25.6(0.06) \\
25.9(0.08) \\
\quad<0.01\end{array}$ & $\begin{array}{l}-1.61(0.04) \\
-1.21(0.05) \\
\quad<0.001\end{array}$ \\
\hline $\begin{array}{l}\text { Returned diet diary } \\
\text { No reply to diet diary } \\
P \text {-value for difference }\end{array}$ & $\begin{array}{l}1785(44) \\
2270(56)\end{array}$ & $\begin{array}{l}56.5(0.11) \\
55.8(0.10) \\
\quad<0.001\end{array}$ & $\begin{array}{l}25.4(0.10) \\
26.4(0.10) \\
\quad<0.001\end{array}$ & $\begin{array}{l}-1.77(0.06) \\
-1.18(0.06) \\
<0.001\end{array}$ \\
\hline
\end{tabular}

NS - not significant.

* Values are mean (standard error).

† Measured by Townsend score. A higher score corresponds to more deprivation. 


\section{Reproducibility of food group questionnaire}

Tables 2 and 3 show results for the reproducibility of the food group questionnaire. Table 2 shows percentage responding yes and kappa values for each of the dietary items for which the question was 'Which types of these items do you eat about once a week or more often?' Table 3 shows the mean reported intakes and the percentage change in reported intakes between baseline and each of the follow-up food group questionnaires.

\section{Short-term comparison}

Over the short term, 84 of the 87 (97\%) yes/no items (Table 2) showed moderate agreement or above. Items for which agreement was only fair included kidney and corn oil or soya oil used in cooking or salads. These items were reported as eaten once a week or more by few women: $2 \%$ for kidney, $10-12 \%$ for corn oil and $1-2 \%$ for soya oil used in cooking or salads. Amounts of food eaten were reported with high consistency (Table 3), with 33 of the 35 items (94\%) changing by less than $10 \%$. Items for which there was a change of $10 \%$ or over were stewed/tinned fruit $(-12 \%)$ and fizzy drinks $(+13 \%)$, although this corresponds to less than 1 portion per day.

\section{Seasonal comparison}

For the seasonal, winter to summer comparison, 75 of the 87 (86\%) items showed at least moderate agreement. Yes/no items (Table 2) showing only fair agreement included the meat products kidney, liver/pâté and beefburger/hamburger; these items were eaten by a low proportion of the study population, $2 \%$ or less for kidney and beefburger/hamburger and 7-8\% for liver/pâté. The vegetable item Brussels sprouts was reported as eaten by $49 \%$ of women at the baseline food group questionnaire (during the winter season) and only $23 \%$ in the summer seasonal repeat food group questionnaire. In addition, a number of items relating to the types of fat eaten showed only fair repeatability, including soft cheese, mayonnaise or salad cream spread on bread, etc., soft margarine, corn oil, mayonnaise, soya oil used in cooking/salads, and the item never use milk/cream. Amounts of food consumed (Table 3) varied by less than 10\% for 27 of the 35 items (77\%). Those for which the amount reported varied by $10 \%$ or more were salad items/raw vegetables $(+23 \%)$, dried fruit $(+29 \%)$, cakes/buns/puddings/pies $(-10 \%)$, gravy $(-11 \%)$, glasses of milk/hot chocolate $(+13 \%)$, fizzy drinks $(+10 \%)$, water $(+20 \%)$ and fruit squash $(+21 \%)$.

\section{Long-term comparisons}

Over the long term, the patterns were very similar across 1- and 2-year comparisons. The vast majority of items were reported with at least moderate agreement (80\% and 83\% for 1- and 2-year comparisons, respectively). For the 1-year comparisons, yes/no items showing only fair agreement (Table 2) were the meat product kidney, the vegetable aubergine, and a number of items relating to types of fat spread on bread or in cooking or salads. Similarly, for the 2-year comparisons, the meat product kidney and the items relating to types of fat spread on bread or used in cooking or salads, along with the meat products liver/pâté and beefburger/hamburger, and cod/ haddock/white fish showed only fair agreement. Also showing only fair agreement for both the 1-year and 2 -year comparisons were the items soya milk and never use milk/cream. Amounts of food consumed differed by less than $10 \%$ for $89 \%$ and $86 \%$ for the 1 - and 2 -year comparisons, respectively (Table 3 ). Items for which there was a difference of $10 \%$ or over in the amount reported eaten for the 1-year comparison were dried fruit $(+13 \%)$, fizzy drinks $(-12 \%)$, water $(+10 \%)$ and fruit squash $(+15 \%)$. For the 2-year comparison, those items for which there was a difference of $10 \%$ or more were fish/seafood $(+10 \%)$, nuts $(+11 \%)$, fizzy drinks $(-18 \%)$, water $(+13 \%)$ and fruit squash $(+11 \%)$.

\section{Summary of reproducibility}

Of the 87 items, 65 (75\%) showed at least moderate agreement across all four time-point comparisons. Over half of the items showing only fair or poor agreement related to types of fat intake, either as spreads used on bread or used in cooking or salad dressing, and only three items (3\%) showed consistently poor agreement for all four time-point comparisons. Virtually all of the vegetable items showed agreement that was moderate or better; two showed fair agreement but only for one time-point comparison. For the remainder of the items with at least one comparison showing fair agreement or worse, few respondents reported eating these items once a week or more often.

The percentage change was under $20 \%$ for all except four of the 140 comparisons; most notable was the intake of salad/raw vegetable items, consumption of which increased by $23 \%$ in the seasonal repeat compared with baseline. For the other three comparisons exceeding 20\%, both intake and the number of responses were very low. Repeating the analysis assuming that a blank response represented a zero intake produced a very similar pattern of results.

\section{Performance of food group questionnaire compared with 7-day diet diary for estimating nutrient intakes}

Table 4 shows a comparison of the daily nutrient intake data estimated from the 7-day diet diary and the baseline food group questionnaire. There were a number of significant differences between the absolute median nutrient intakes estimated from the 7-day diet diary and the food group questionnaire. The largest disagreements were seen for total fat $(+25 \%)$, monounsaturated fat $(+46 \%)$, polyunsaturated fat $(+59 \%)$, alcohol $(-39 \%)$, carotene $(-61 \%)$, vitamin $\mathrm{D}(+27 \%)$, and vitamin $\mathrm{E}(+36 \%)$. However, 
Table 2 Kappa values for agreement between responses at baseline and each of the repeat food group questionnaires to the question 'Which types of these items do you eat about once a week or more often?'

\begin{tabular}{|c|c|c|c|c|c|c|c|c|c|}
\hline & \multirow{2}{*}{$\begin{array}{c}\begin{array}{c}\text { Baseline } \\
n=12221 \\
\text { Nov/Dec } 1999\end{array} \\
\% \text { yes }\end{array}$} & \multicolumn{2}{|c|}{$\begin{array}{c}\text { Short-term } \\
\text { (3 months) } \\
n=1288 \\
\text { Feb/March } 2000\end{array}$} & \multicolumn{2}{|c|}{$\begin{array}{c}\text { Seasonal } \\
(6 \text { months }) \\
n=1217 \\
\text { May/June } 2000\end{array}$} & \multicolumn{2}{|c|}{$\begin{array}{c}\text { Long-term } \\
\text { (1 year) } \\
n=1287 \\
\text { Nov/Dec } 2000\end{array}$} & \multicolumn{2}{|c|}{$\begin{array}{c}\text { Long-term } \\
\text { (2 year) } \\
n=1271 \\
\text { Nov/Dec } 2001\end{array}$} \\
\hline & & $\%$ yes & Kappa & $\%$ yes & Kappa & $\%$ yes & Kappa & $\%$ yes & Kappa \\
\hline \multicolumn{10}{|l|}{ Meat } \\
\hline Beef & 55 & 58 & 0.69 & 51 & 0.60 & 51 & 0.63 & 54 & 0.60 \\
\hline Bacon & 39 & 42 & 0.62 & 39 & 0.55 & 39 & 0.53 & 41 & 0.54 \\
\hline Chicken/poultry & 91 & 92 & 0.68 & 92 & 0.64 & 92 & 0.60 & 91 & 0.60 \\
\hline Lamb & 41 & 41 & 0.61 & 39 & 0.60 & 41 & 0.59 & 40 & 0.59 \\
\hline Ham & 37 & 39 & 0.52 & 41 & 0.45 & 37 & 0.40 & 40 & 0.45 \\
\hline Kidney & 2 & 2 & 0.33 & 2 & 0.39 & 2 & 0.25 & 2 & 0.36 \\
\hline Pork & 45 & 47 & 0.64 & 41 & 0.60 & 43 & 0.56 & 42 & 0.57 \\
\hline Sausages & 24 & 25 & 0.61 & 22 & 0.52 & 26 & 0.51 & 24 & 0.53 \\
\hline Liver/pâté & 8 & 8 & 0.49 & 7 & 0.35 & 8 & 0.40 & 7 & 0.32 \\
\hline Beefburger/hamburger & 2 & 2 & 0.44 & 1 & 0.25 & 2 & 0.43 & 1 & 0.34 \\
\hline Never eat meat & 3 & 3 & 0.92 & 4 & 0.83 & 3 & 0.87 & 4 & 0.81 \\
\hline \multicolumn{10}{|l|}{ Fish } \\
\hline Tuna & 43 & 44 & 0.70 & 49 & 0.63 & 44 & 0.54 & 46 & 0.56 \\
\hline Trout & 8 & 9 & 0.58 & 8 & 0.49 & 8 & 0.54 & 7 & 0.47 \\
\hline Mackerel & 11 & 11 & 0.60 & 13 & 0.53 & 13 & 0.51 & 15 & 0.45 \\
\hline Fish \& chips & 16 & 15 & 0.50 & 15 & 0.54 & 16 & 0.40 & 16 & 0.44 \\
\hline Salmon & 39 & 39 & 0.62 & 41 & 0.58 & 38 & 0.58 & 43 & 0.52 \\
\hline Sardines & 13 & 13 & 0.62 & 15 & 0.58 & 16 & 0.56 & 16 & 0.47 \\
\hline Other seafood & 18 & 18 & 0.58 & 20 & 0.49 & 17 & 0.45 & 20 & 0.47 \\
\hline Cod/haddock/white fish & 69 & 70 & 0.54 & 67 & 0.56 & 68 & 0.52 & 67 & 0.39 \\
\hline Never eat fish & 3 & 3 & 0.72 & 3 & 0.81 & 3 & 0.80 & 2 & 0.77 \\
\hline \multicolumn{10}{|l|}{ Vegetables } \\
\hline Green peas & 70 & 70 & 0.64 & 72 & 0.55 & 71 & 0.53 & 74 & 0.51 \\
\hline Tomatoes & 90 & 88 & 0.54 & 94 & 0.55 & 89 & 0.53 & 92 & 0.41 \\
\hline Green beans & 59 & 54 & 0.54 & 58 & 0.45 & 59 & 0.48 & 65 & 0.46 \\
\hline Broccoli & 75 & 77 & 0.68 & 77 & 0.63 & 75 & 0.58 & 75 & 0.51 \\
\hline Onions & 79 & 80 & 0.60 & 78 & 0.56 & 78 & 0.53 & 78 & 0.53 \\
\hline Baked beans & 52 & 50 & 0.67 & 52 & 0.62 & 51 & 0.54 & 51 & 0.55 \\
\hline Cabbage & 55 & 53 & 0.65 & 51 & 0.57 & 57 & 0.58 & 55 & 0.53 \\
\hline Garlic & 42 & 42 & 0.73 & 42 & 0.70 & 40 & 0.70 & 42 & 0.68 \\
\hline Soya meat/tofu & 4 & 3 & 0.58 & 4 & 0.55 & 4 & 0.40 & 4 & 0.51 \\
\hline Carrots & 89 & 90 & 0.59 & 88 & 0.49 & 89 & 0.52 & 90 & 0.48 \\
\hline Swede & 32 & 36 & 0.60 & 21 & 0.50 & 32 & 0.59 & 28 & 0.54 \\
\hline Chick peas/lentils & 10 & 8 & 0.55 & 9 & 0.62 & 8 & 0.50 & 11 & 0.48 \\
\hline Courgettes & 29 & 27 & 0.61 & 31 & 0.63 & 26 & 0.63 & 30 & 0.59 \\
\hline Spinach & 15 & 15 & 0.70 & 16 & 0.61 & 14 & 0.60 & 16 & 0.54 \\
\hline Cauliflower & 63 & 59 & 0.54 & 57 & 0.57 & 61 & 0.52 & 61 & 0.51 \\
\hline Beetroot & 25 & 25 & 0.61 & 31 & 0.45 & 25 & 0.49 & 27 & 0.46 \\
\hline Sweet corn & 25 & 24 & 0.60 & 27 & 0.54 & 23 & 0.51 & 23 & 0.45 \\
\hline Green/red peppers & 46 & 41 & 0.68 & 48 & 0.65 & 42 & 0.63 & 45 & 0.59 \\
\hline Leeks & 35 & 39 & 0.66 & 26 & 0.49 & 34 & 0.56 & 31 & 0.55 \\
\hline Avocado & 8 & 10 & 0.65 & 12 & 0.51 & 9 & 0.54 & 11 & 0.54 \\
\hline Brussels sprouts & 49 & 53 & 0.57 & 23 & 0.36 & 48 & 0.54 & 39 & 0.54 \\
\hline Parsnip & 39 & 42 & 0.53 & 24 & 0.44 & 38 & 0.56 & 32 & 0.49 \\
\hline Aubergine & 8 & 6 & 0.49 & 5 & 0.44 & 4 & 0.35 & 6 & 0.55 \\
\hline Mushrooms & 67 & 63 & 0.66 & 63 & 0.59 & 64 & 0.55 & 65 & 0.54 \\
\hline Lettuce & 72 & 74 & 0.56 & 85 & 0.43 & 71 & 0.55 & 75 & 0.48 \\
\hline Celery & 34 & 38 & 0.65 & 38 & 0.60 & 32 & 0.57 & 33 & 0.56 \\
\hline Cucumber & 59 & 58 & 0.66 & 70 & 0.54 & 58 & 0.60 & 62 & 0.58 \\
\hline \multicolumn{10}{|l|}{ Fruit } \\
\hline Apples & 81 & 78 & 0.70 & 77 & 0.53 & 79 & 0.61 & 82 & 0.51 \\
\hline Bananas & 86 & 84 & 0.74 & 87 & 0.65 & 85 & 0.61 & 86 & 0.61 \\
\hline Oranges, satsumas & 64 & 71 & 0.56 & 62 & 0.56 & 64 & 0.52 & 61 & 0.51 \\
\hline Grapefruit & 24 & 23 & 0.71 & 24 & 0.59 & 23 & 0.56 & 23 & 0.50 \\
\hline Pears & 51 & 48 & 0.66 & 46 & 0.57 & 50 & 0.54 & 51 & 0.47 \\
\hline Stone fruit & 58 & 51 & 0.51 & 67 & 0.45 & 55 & 0.44 & 61 & 0.46 \\
\hline \multicolumn{10}{|l|}{ Cereals } \\
\hline Bran cereal & 26 & 26 & 0.75 & 28 & 0.64 & 27 & 0.62 & 25 & 0.54 \\
\hline Muesli & 26 & 24 & 0.70 & 30 & 0.61 & 24 & 0.56 & 25 & 0.53 \\
\hline Biscuit cereal & 25 & 25 & 0.71 & 28 & 0.58 & 25 & 0.52 & 27 & 0.51 \\
\hline Other & 29 & 30 & 0.61 & 29 & 0.55 & 29 & 0.51 & 32 & 0.44 \\
\hline Oat cereal & 27 & 28 & 0.65 & 20 & 0.52 & 27 & 0.55 & 25 & 0.48 \\
\hline
\end{tabular}


Table 2 Continued

\begin{tabular}{|c|c|c|c|c|c|c|c|c|c|}
\hline & \multirow{2}{*}{$\begin{array}{c}\begin{array}{c}\text { Baseline } \\
n=12221 \\
\text { Nov/Dec } 1999 \\
\% \text { yes }\end{array}\end{array}$} & \multicolumn{2}{|c|}{$\begin{array}{c}\text { Short-term } \\
\text { (3 months) } \\
n=1288 \\
\text { Feb/March } 2000\end{array}$} & \multicolumn{2}{|c|}{$\begin{array}{c}\text { Seasonal } \\
(6 \text { months }) \\
n=1217 \\
\text { May/June } 2000\end{array}$} & \multicolumn{2}{|c|}{$\begin{array}{c}\text { Long-term } \\
(1 \text { year) } \\
n=1287 \\
\text { Nov/Dec } 2000\end{array}$} & \multicolumn{2}{|c|}{$\begin{array}{c}\text { Long-term } \\
\text { (2 year) } \\
n=1271 \\
\text { Nov/Dec } 2001\end{array}$} \\
\hline & & $\%$ yes & Kappa & $\%$ yes & Kappa & $\%$ yes & Kappa & $\%$ yes & Kappa \\
\hline \multicolumn{10}{|l|}{ Fats spread on bread, etc. } \\
\hline Butter & 36 & 37 & 0.77 & 33 & 0.73 & 34 & 0.68 & 36 & 0.61 \\
\hline Margarine & 10 & 9 & 0.48 & 10 & 0.50 & 9 & 0.41 & 8 & 0.44 \\
\hline Soft cheese & 14 & 14 & 0.45 & 13 & 0.40 & 13 & 0.25 & 11 & 0.31 \\
\hline Low-fat spread & 49 & 50 & 0.67 & 47 & 0.66 & 47 & 0.59 & 43 & 0.51 \\
\hline Mayonnaise & 10 & 11 & 0.43 & 13 & 0.40 & 10 & 0.38 & 10 & 0.44 \\
\hline Salad cream & 7 & 8 & 0.43 & 10 & 0.32 & 8 & 0.29 & 7 & 0.28 \\
\hline Olive oil spread & 19 & 18 & 0.75 & 20 & 0.70 & 23 & 0.58 & 24 & 0.58 \\
\hline Marmite & 22 & 20 & 0.59 & 20 & 0.53 & 19 & 0.50 & 19 & 0.49 \\
\hline Rarely use spread & 8 & 7 & 0.60 & 8 & 0.49 & 8 & 0.50 & 8 & 0.38 \\
\hline \multicolumn{10}{|c|}{ Fats used in cooking \& salads } \\
\hline Butter & 13 & 16 & 0.51 & 12 & 0.53 & 13 & 0.47 & 14 & 0.44 \\
\hline Soft margarine & 19 & 18 & 0.41 & 17 & 0.37 & 19 & 0.32 & 18 & 0.33 \\
\hline White Flora & 8 & 8 & 0.58 & 8 & 0.65 & 7 & 0.61 & 7 & 0.57 \\
\hline Olive oil & 54 & 56 & 0.76 & 57 & 0.71 & 56 & 0.70 & 60 & 0.68 \\
\hline Hard margarine & 4 & 4 & 0.44 & 4 & 0.43 & 5 & 0.42 & 3 & 0.32 \\
\hline Lard/dripping & 9 & 10 & 0.62 & 7 & 0.48 & 9 & 0.62 & 7 & 0.52 \\
\hline Corn oil & 12 & 10 & 0.34 & 9 & 0.31 & 9 & 0.28 & 8 & 0.28 \\
\hline Sunflower oil & 44 & 40 & 0.52 & 43 & 0.50 & 41 & 0.48 & 42 & 0.51 \\
\hline Mayonnaise & 21 & 18 & 0.45 & 24 & 0.39 & 18 & 0.35 & 21 & 0.37 \\
\hline Soya oil & 1 & 2 & 0.29 & 1 & 0.11 & 1 & 0.19 & 1 & 0.21 \\
\hline Other vegetable oil & 20 & 19 & 0.47 & 19 & 0.46 & 20 & 0.39 & 18 & 0.43 \\
\hline Salad cream & 15 & 14 & 0.51 & 19 & 0.45 & 16 & 0.38 & 15 & 0.42 \\
\hline \multicolumn{10}{|l|}{ Milk } \\
\hline Full-cream milk & 13 & 12 & 0.80 & 12 & 0.83 & 13 & 0.78 & 11 & 0.71 \\
\hline Single cream & 13 & 12 & 0.53 & 14 & 0.51 & 13 & 0.51 & 12 & 0.49 \\
\hline Semi-skimmed milk & 67 & 68 & 0.86 & 67 & 0.84 & 65 & 0.77 & 65 & 0.71 \\
\hline Double cream & 9 & 11 & 0.53 & 7 & 0.52 & 10 & 0.49 & 9 & 0.43 \\
\hline Skimmed milk & 27 & 26 & 0.88 & 26 & 0.82 & 26 & 0.79 & 28 & 0.79 \\
\hline Ice cream & 17 & 15 & 0.45 & 21 & 0.43 & 15 & 0.43 & 17 & 0.35 \\
\hline Soya milk & 6 & 5 & 0.42 & 4 & 0.51 & 4 & 0.38 & 5 & 0.38 \\
\hline Never have milk/cream & 4 & 3 & 0.43 & 2 & 0.40 & 3 & 0.32 & 2 & 0.32 \\
\hline
\end{tabular}

agreement in the relative ranking by the 7-day diet diary and the food group questionnaire was generally good, with rank correlations of 0.5 or over for nine of the 23 nutrients. Categorising the estimated nutrient intakes from the food group questionnaire and the 7-day diet diary into tertiles and assessing same classification (at least $45 \%$ classified into the same tertile by both methods) and extreme misclassification (e.g. lowest tertile using the food group questionnaire and highest tertile using the 7-day diet diary of at most $5 \%$ by both methods) showed consistently favourable performance for carbohydrate, saturated fat, cholesterol, total sugars, alcohol, fibre, calcium, riboflavin, folate, and vitamin C. These favourable ratings corresponded with weighted kappa values above 0.3 .

Energy adjustment generally improved the measures of agreement considered in respect of the macronutrients, but the measures of agreement either declined or remained approximately the same for the micronutrients. Energy-adjusted nutrients that could be considered to have good agreement included all those for which unadjusted agreement was good, along with total fat.
Excluding those people who were classified as having an unreliable energy intake gave a similar pattern of results, with the same nutrients being consistently well estimated using both dietary assessment methods (results not shown).

\section{Discussion}

The data show excellent repeatability for the food group questionnaire over comparisons from 3 months to 2 years, giving confidence in the data collected using this questionnaire method. The small number of items that showed consistently poor repeatability were items relating to the types of fats eaten or used in cooking and items which were on average consumed in relatively small amounts, highlighting some of the aspects of diet about which it is difficult to capture information reliably. Using the diet diary as a reference, we showed that nutrient estimation using the food group questionnaire is reasonable for a selection of the nutrients studied. Recruitment into the Million Women Study and hence the follow-up, including the food group questionnaire, 
Table 3 Percentage change in reported intakes between baseline and each of the repeat food group questionnaires

\begin{tabular}{|c|c|c|c|c|c|c|c|c|c|c|}
\hline \multirow[b]{2}{*}{ Item } & \multirow{2}{*}{$\begin{array}{l}\text { Portion size } \\
\text { (per week) }\end{array}$} & \multirow{2}{*}{$\begin{array}{c}\text { Baseline } \\
n=12221 \\
\text { Nov/Dec } 1999 \\
\text { Mean }\end{array}$} & \multicolumn{2}{|c|}{$\begin{array}{c}\text { Short-term } \\
(3 \text { months }) \\
n=1288 \\
\text { Feb/March } 2000\end{array}$} & \multicolumn{2}{|c|}{$\begin{array}{c}\text { Seasonal } \\
(6 \text { months }) \\
n=1217 \\
\text { May/June } 2000\end{array}$} & \multicolumn{2}{|c|}{$\begin{array}{c}\text { Long-term } \\
\text { (1 year) } \\
n=1287 \\
\text { Nov/Dec } 2000\end{array}$} & \multicolumn{2}{|c|}{$\begin{array}{c}\text { Long-term } \\
\text { (2 years) } \\
n=1271 \\
\text { Nov/Dec } 2001\end{array}$} \\
\hline & & & Mean & \% Change & Mean & $\%$ Change & Mean & $\%$ Change & Mean & $\%$ Change \\
\hline Meat & portions & 4.8 & 5.1 & 5 & 4.7 & -3 & 4.9 & 2 & 4.7 & -1 \\
\hline Fish/seafood & portions & 2.1 & 2.1 & 1 & 2.3 & 7 & 2.2 & 3 & 2.3 & 10 \\
\hline Chips & portions & 0.9 & 0.8 & -2 & 0.9 & 1 & 0.9 & 2 & 0.9 & 3 \\
\hline Potatoes (not chips) & portions & 4.2 & 4.4 & 4 & 4.0 & -4 & 4.2 & -1 & 4.1 & -4 \\
\hline Pasta/spaghetti & portions & 1.5 & 1.4 & -4 & 1.5 & 5 & 1.5 & 3 & 1.4 & -2 \\
\hline Rice & portions & 1.2 & 1.2 & 2 & 1.2 & 1 & 1.2 & -1 & 1.2 & -1 \\
\hline Cheese & portions & 3.0 & 3.1 & 1 & 3.0 & -1 & 3.0 & -1 & 3.0 & -2 \\
\hline Eggs & number & 2.4 & 2.4 & 1 & 2.5 & 4 & 2.6 & 7 & 2.4 & -1 \\
\hline Cooked vegetables & tablespoons & 13.1 & 13.0 & -1 & 12.2 & -7 & 13.3 & 2 & 13.3 & 2 \\
\hline Salad/raw vegetables & tablespoons & 8.2 & 7.9 & -4 & 10.1 & 23 & 8.5 & 3 & 8.9 & 8 \\
\hline Fresh fruit & pieces & 11.5 & 11.2 & -3 & 12.3 & 7 & 11.4 & -1 & 11.9 & 3 \\
\hline Dried fruit & pieces & 3.5 & 3.4 & -2 & 4.5 & 29 & 3.9 & 13 & 3.5 & 2 \\
\hline Fruit juice & glasses & 4.9 & 4.8 & -3 & 5.4 & 9 & 5.2 & 5 & 4.8 & -4 \\
\hline Stewed/tinned fruit & tablespoons & 2.7 & 2.4 & -12 & 2.7 & -2 & 2.6 & -4 & 2.6 & -5 \\
\hline White bread & slices & 7.9 & 7.4 & -6 & 7.8 & -1 & 7.9 & 0 & 7.4 & -6 \\
\hline Brown/wholemeal bread & slices & 9.8 & 9.7 & -2 & 10.0 & 2 & 9.1 & -7 & 9.2 & -7 \\
\hline Crackers/crispbread & number & 4.8 & 5.0 & 4 & 4.9 & 2 & 4.7 & -3 & 4.8 & 0 \\
\hline Crisps & packets & 1.3 & 1.3 & 2 & 1.2 & -8 & 1.3 & 3 & 1.4 & 9 \\
\hline Sweet biscuits & number & 6.1 & 5.7 & -6 & 5.9 & -3 & 6.0 & -2 & 5.7 & -7 \\
\hline Dairy desserts & number & 3.9 & 3.7 & -6 & 4.2 & 6 & 4.1 & 4 & 4.2 & 6 \\
\hline Cakes \& puddings & number & 3.1 & 3.0 & -4 & 2.8 & -10 & 3.2 & 2 & 2.9 & -6 \\
\hline Chocolate & pieces & 3.6 & 3.8 & 4 & 3.6 & 1 & 3.9 & 9 & 3.8 & 5 \\
\hline Boiled sweets & number & 3.8 & 3.5 & -8 & 3.6 & -5 & 3.8 & 2 & 3.5 & -7 \\
\hline Nuts & tablespoons & 1.4 & 1.5 & 6 & 1.4 & -4 & 1.4 & -1 & 1.6 & 11 \\
\hline Gravy \& cream sauces & tablespoons & 5.4 & 5.1 & -4 & 4.8 & -1 & 5.6 & 4 & 5.2 & -3 \\
\hline Jam/marmalade & tablespoons & 2.2 & 2.1 & -7 & 2.2 & 0 & 2.3 & 2 & 2.1 & -5 \\
\hline Breakfast cereal & bowls & 5.1 & 5.0 & -2 & 5.1 & 1 & 5.1 & 1 & 5.1 & 0 \\
\hline Alcohol & drinks & 4.6 & 4.6 & 1 & 4.3 & -5 & 4.4 & -4 & 4.9 & 6 \\
\hline Tea & cups/day & 3.8 & 4.0 & 4 & 3.8 & 0 & 3.7 & -3 & 3.8 & -2 \\
\hline Milk/hot chocolate & cups/day & 0.7 & 0.7 & -5 & 0.8 & 13 & 0.7 & -2 & 0.7 & -5 \\
\hline Fizzy drinks & glasses/day & 0.7 & 0.8 & 13 & 0.8 & 10 & 0.7 & -12 & 0.6 & -18 \\
\hline Coffee & cups/day & 2.5 & 2.6 & 1 & 2.5 & -3 & 2.5 & -3 & 2.4 & -6 \\
\hline Water & glasses/day & 2.9 & 3.0 & 6 & 3.4 & 20 & 3.2 & 10 & 3.2 & 13 \\
\hline Fruit squash & glasses/day & 0.8 & 0.9 & 9 & 1.0 & 21 & 0.9 & 15 & 0.9 & 11 \\
\hline Sugar & teaspoons/day & 1.3 & 1.3 & 2 & 1.4 & 5 & 1.3 & -4 & 1.2 & -9 \\
\hline
\end{tabular}

necessarily took place over a number of years. Hence the stability of responses to the food group questionnaire and the lack of any major time shift in reported dietary patterns, alongside the ability to estimate a range of nutrients, gives confidence that the dietary data collected can be utilised in future analyses of long-term consumption and disease.

While there were appreciable differences in certain vegetable items between the baseline (winter) questionnaire and the seasonal (summer) comparison questionnaire, these are likely to reflect true variation in the diet from winter to summer. The availability of the winter vegetable Brussels sprouts falls markedly throughout the summer, and the consumption of salad vegetables is likely to be higher during months of warmer weather. The longterm changes detected in the consumption of fluids are interesting; it is suggestive of an overall increase in consumption coupled with a switch from fizzy drinks to water and fruit squash. This pattern would be consistent with a trend towards a more health-conscious choice of drinks and may reflect a real change in behaviour.
The performance component of the current paper compared the nutrient intakes estimated using the 7-day diet diary with those from the food group questionnaire. We have assumed that the 7-day diaries represent the reference measurement, which is our most accurate estimate of nutrient intake. Ideally nutrient biomarkers should be the standard by which to judge the validity of any dietary assessment tool as has been shown in recent publications ${ }^{23,24}$; however, their use remains limited as adequate biomarkers do not exist for some key components of the diet such as total fat and fibre. Comparing nutrient intakes estimated from the food group questionnaire with those from the 7-day diet diaries has shown that carbohydrate, saturated fat, cholesterol, total sugars, alcohol, fibre, calcium, riboflavin, folate and vitamin $\mathrm{C}$ performed consistently well in terms of their rank correlations, percentage correct classification when the data were categorised into tertiles and weighted kappa statistics. However, since the reporting errors associated with the food group questionnaire and the 7-day diet diary are likely to be highly correlated, it is possible that the 


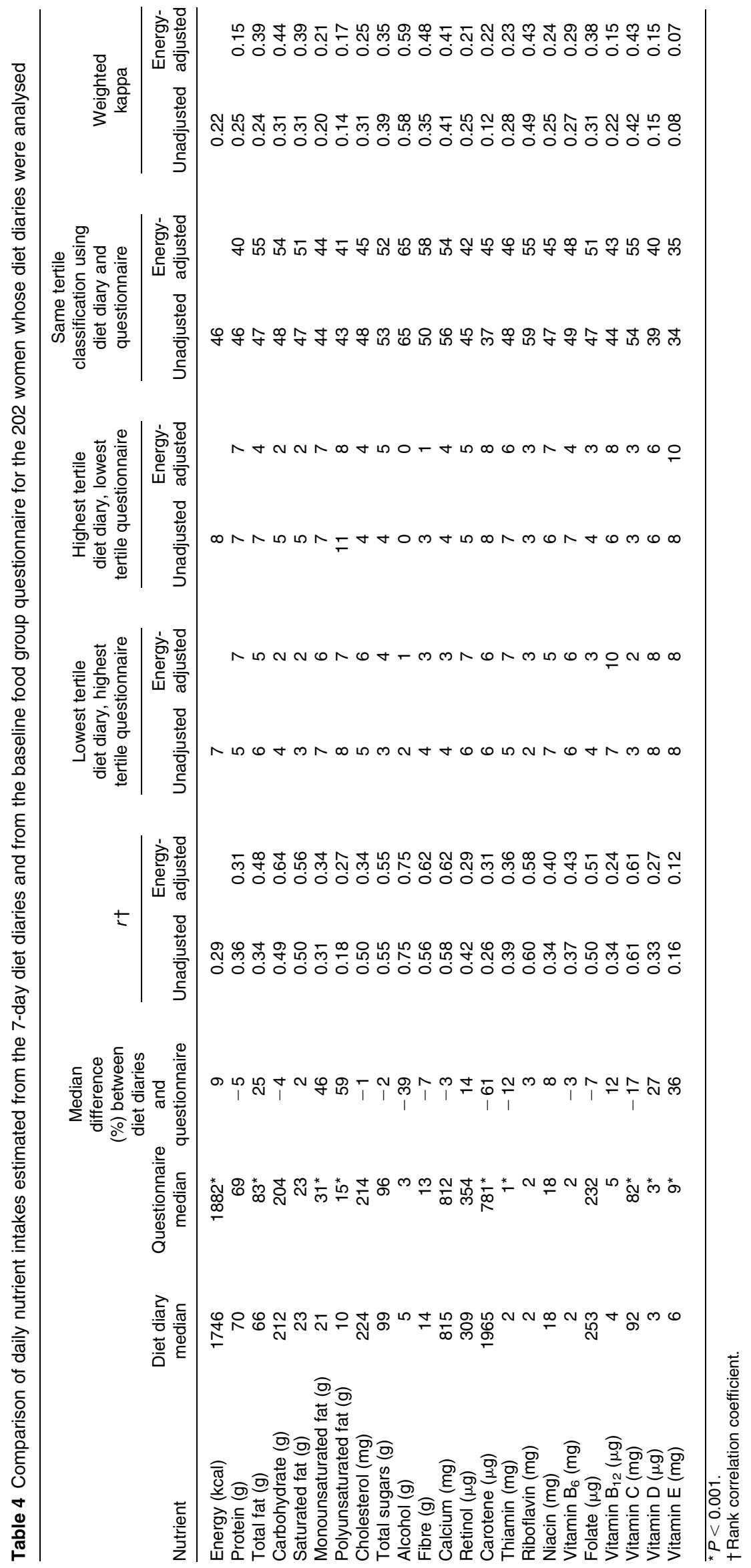


degree of agreement has been overstated ${ }^{25}$. While it is possible to estimate intakes of these nutrients, care is required in their use in future epidemiological studies of diet-disease relationships using the complete Million Women Study dataset.

Although it appears that the food group questionnaire was not able to reliably capture information relating to the consumption of rare or unpopular food items, it should be remembered that it was designed solely to capture information on major sources of variation in the diet, allowing classification of the women into appropriate groups. It was never expected that it would be suitable to capture entire diets, and as such was designed less like a classical FFQ and more like a shopping list. Additionally, it was kept brief to allow computerised data entry and to maximise compliance so as to gather information from as many study participants as possible. These results therefore give confidence in the future use of the food group questionnaire to allow categorisation of study participants in the Million Women Study according to a wide range of dietary exposures in disease-specific analyses.

Most FFQs are not designed to assess total energy intake accurately, and this also applies to the Million Women Study food group questionnaire. However, energy intake using the questionnaire was moderately well estimated, suggesting that the portion sizes allocated to food items in the questionnaire and the diet diary were reasonably accurate allowing participants to be similarly ranked according to energy intake by both methods. It can be hypothesised that energy-adjusted nutrients may be a better measure of relative intake as the adjustment may partially correct for measurement error. It is interesting to note that in the present analysis a beneficial effect of energy adjustment was mainly seen in terms of the macronutrients which could be considered as directly contributing to total energy, whereas energy-adjusted micronutrients had, on the whole, similar or worse agreement. Notably, energy adjustment did not improve the correlations for protein intake, which may indicate that there are differential reporting errors across the macronutrients. Energy adjustment yielded a considerable improvement in the measures of agreement of total fat intake between the food group questionnaire and the 7-day diet diary such that an energy-adjusted total fat intake could be used in future studies. The results suggest that energy-adjusted nutrient analyses should be considered on a case-by-case basis, as it may be the situation that absolute intakes of nutrients are important aetiologically.

Capturing information on habitual diet is potentially subject to much measurement error, and therefore selecting only those nutrients that not only have a high rank correlation but also a small misclassification rate will go some way to minimise the impact that measurement error may have on detecting diet-disease associations. A major feature of the Million Women Study is the size of the population for which exposure information is available. Based on current response rates, the Million Women Study is likely to have dietary information on over 800000 participants. While it is well known that measurement error not only attenuates a diet-disease relationship ${ }^{2}$ but also reduces the power to detect the association $^{26}$, such a large sample size should allow the detection of relatively modest diet-disease effects.

Three other studies have examined the reproducibility of food group data ${ }^{27-29}$. Pietinen et al. $^{29}$ examined the proportion of participants falling in the same frequency of intake category for various food groups in a Finnish study. When the food group consumption data were categorised into tertiles, exact agreement between the two questionnaires was $36 \%$ on average; agreement was better for foods eaten daily such as potatoes or for foods eaten rarely such as kidney and liver dishes, wheat bran and germ. Ocke et al. ${ }^{28}$ showed correlations for women ranging from 0.61 for vegetables to 0.91 for alcoholic beverages over 6 months and from 0.63 for fish to 0.92 for alcoholic beverages over 12 months. Bohlscheid-Thomas et al. ${ }^{27}$ reported that median differences in intake over a 6-month comparison were within $\pm 10 \%$ for half the food groups and that correlation coefficients ranged from 0.49 for bread to 0.89 for alcoholic beverages. Dietary pattern differences between these study groups may account for specific differences, but overall the results we present here fall within the range of reproducibility previously reported.

Brunner et $a l^{3}$ compared nutrient intakes estimated from a 7-day diet diary with those from an FFQ. For the women in their study (low energy reporters excluded), Spearman's rank correlations ranged from 0.22 for energy to 0.86 for alcohol, median of 0.37 , comparable with our range from 0.16 for vitamin $\mathrm{E}$ to 0.75 for alcohol with a median value of 0.41 . Brunner's group also examined agreement across quartiles of intake: exact quartile agreement achieved ranged from $29 \%$ for carotenes to $65 \%$ for alcohol, with a median of $35 \%$; in our study we found exact agreement into tertiles ranged from 34\% for vitamin $\mathrm{E}$ to $65 \%$ for alcohol, median value $47 \%$. Willett et al. $^{30}$ also reported a comparison of nutrient data from an FFQ versus a diet diary. Comparing the average of four 7-day dietary records with the initial administration of an FFQ, Pearson correlation coefficients ranged from 0.18 for protein to 0.52 for sucrose with a median of 0.32 .

In summary, the short, simple and easy-to-administer, computerised questionnaire used in this study has been shown not only to be reproducible over time but also to be reasonably accurate for the assessment of a number of dietary nutrients in comparison with a 7-day diet diary. This may permit future analyses into relationships between diet and disease by allowing individuals to be categorised by either their reported eating habits or their estimated nutrient intakes. 


\section{Acknowledgements}

We thank all of the women participating in the Million Women Study and the staff at collaborating National Health Service Breast Screening Centres. The Million Women Study is supported by the UK Medical Research Council, Cancer Research UK and the UK National Health Service Breast Screening Programme.

\section{References}

1 Bingham SA, Day NE. Using biochemical markers to assess the validity of prospective dietary assessment methods and the effect of energy adjustment. American Journal of Clinical Nutrition 1997; 65: 1130S-7S.

2 Willett W. Nutritional Epidemiology, 2nd ed. New York: Oxford University Press, 1998.

3 Brunner E, Stallone D, Juneja M, Bingham SA, Marmot M. Dietary assessment in Whitehall II: comparison of $7 \mathrm{~d}$ diet diary and food-frequency questionnaire and validity against biomarkers. British Journal of Nutrition 2001; 86: 405-14.

4 The Million Women Study Collaborative Group. The Million Women Study: design and characteristics of the study population. Breast Cancer Research 1999; 1: 73-80.

5 Townsend P, Phillimore P, Beattie A. Health and Deprivation: Inequality and the North. London: Croom Helm, 1988.

6 Ministry of Agriculture, Fisheries and Food. Food Portion Sizes, 2nd ed. London: HMSO, 1993.

7 Holland B, Welch AA, Unwin ID, Buss DH, Paul AA, Southgate DAT. McCance \& Widdowson's The Composition of Foods, 5th ed. Cambridge: The Royal Society of Chemisty and Ministry of Agriculture, Fisheries and Food, 1991.

8 Holland B, Unwin ID, Buss DH. Fruit and Nuts. First Supplement to McCance \& Widdowson's The Composition of Foods, 5th ed. Cambridge: Royal Society of Chemistry, 1992.

9 Holland B, Welch AA, Buss DH. Vegetable Dishes. Second Supplement to McCance E Widdowson's The Composition of Foods, 5th ed. Cambridge: Royal Society of Chemistry, 1992.

10 Holland B, Brown J, Buss DH. Fish and Fish Products. Third Supplement to McCance \& Widdowson's The Composition of Foods, 5th ed. Cambridge: Royal Society of Chemistry, 1993.

11 Holland B, Welch AA, Buss DH. Miscellaneous Foods. Fourth Supplement to McCance E Widdowson's The Composition of Foods, 5th ed. Cambridge: Royal Society of Chemistry, 1994.

12 Chan W, Brown J, Lee SM, Buss DH. Meat, Poultry and Game. Fifth Supplement to McCance \& Widdowson's The Composition of Foods, 5th ed. Cambridge: Royal Society of Chemistry, 1995.

13 Chan W, Brown J, Church SM, Buss DH. Meat Products and Dishes. Sixth Supplement to McCance \& Widdowson's The Composition of Foods, 5 th ed. Cambridge: Royal Society of Chemistry, 1996.

14 Holland B, Unwin ID, Buss DH. Cereals and Cereal Products. Third Supplement to McCance \& Widdowson's The Composition of Foods, 4th ed. Cambridge: Royal Society of Chemistry, 1988.

15 Holland B, Unwin ID, Buss DH. Milk Products and Eggs. Fourth Supplement to McCance \& Widdowson's The Composition of Foods, 4th ed. Cambridge: Royal Society of Chemistry, 1989.

16 Holland B, Unwin ID, Buss DH. Vegetables, Herbs and Spices. Fifth Supplement to McCance \& Widdowson's The
Composition of Foods, 4th ed. Cambridge: Royal Society of Chemistry, 1991.

17 Davey GK, Spencer EA, Appleby PN, Allen NE, Knox KH, Key TJ. EPIC-Oxford: lifestyle characteristics and nutrient intakes in a cohort of 33883 meat-eaters and 31546 non meat-eaters in the UK. Public Health Nutrition 2003; 6: $259-68$.

18 Tinuviel Software. WISP Version 2.0. Warrington, UK: Tinuviel Software, 2002.

19 Department of Health. Dietary Reference Values for Food Energy and Nutrients for the United Kingdom. Report of the Panel on Dietary Reference Values of the Committee on Medical Aspects of Food Policy. London: The Stationery Office, 1991.

20 Altman DG. Practical Statistics for Medical Research. London: Chapman \& Hall, 1991; 404-9.

21 Fleiss JL, Cohen J. The equivalence of weighted kappa and the intraclass correlation coefficient as measures of reliability. Educational and Psychological Measurement 1973; 33: 613-9.

22 R Development Core Team. R: A Language and Environment for Statistical Computing. Vienna: R Foundation for Statistical Computing, 2003.

23 Slimani N, Bingham SA, Runswick S, Ferrari P, Day NE, Welch AA, et al. Group level validation of protein intakes estimated by 24-hour diet recall and dietary questionnaires against 24-hour urinary nitrogen in the European Prospective Investigation into Cancer and Nutrition (EPIC) calibration study. Cancer Epidemiology, Biomarkers $\mathcal{E}$ Prevention 2003; 12: 784-95.

24 Subar AF, Kipnis V, Toriano RP, Midthune D, Schoeller DA, Bingham SA, et al. Using intake biomarkers to evaluate the extent of dietary misreporting in a large sample of adults: The OPEN study. American Journal of Epidemiology 2003; 158: $1-13$.

25 Kipnis V, Midthune D, Freedman L, Bingham S, Day NE, Riboli E, et al. Bias in dietary-report instruments and its implications for nutritional epidemiology. Public Health Nutrition 2002; 5: 915-23.

26 McKeown-Eyssen GC, Tibshirani R. Implications of measurement error in exposure for the sample sizes of case-control studies. American Journal of Epidemiology 1994; 139: 415-21.

27 Bohlscheid-Thomas S, Hoting I, Boeing H, Wahrendorf J. Reproducibility and relative validity of food group intake in a food frequency questionnaire developed for the German part of the EPIC project. European Prospective Investigation into Cancer and Nutrition. International Journal of Epidemiology 1997; 26(Suppl. 1): S59-S70.

28 Ocke MC, Bueno-de-Mesquita HB, Goddijn HE, Jansen A, Pols MA, van Staveren WA, et al. The Dutch EPIC food frequency questionnaire. I. Description of the questionnaire, and relative validity and reproducibility for food groups. International Journal of Epidemiology 1997; 26(Suppl. 1): S37-S48.

29 Pietinen P, Hartman AM, Haapa E, Rasanen L, Haapakoski J, Palmgren J, et al. Reproducibility and validity of dietary assessment instruments. II. A qualitative food frequency questionnaire. American Journal of Epidemiology 1988; 128: $667-76$.

30 Willett WC, Sampson L, Stampfer MJ, Rosner B, Bain C, Witschi J, et al. Reproducibility and validity of a semiquantitative food frequency questionnaire. American Journal of Epidemiology 1985; 122: 51-65. 


\section{Appendix - Short food group questionnaire used in the Million Women Study}

1. Which types of meat do you eat about once a week or more often? (you can cross more than one box)

$\begin{array}{llll}\text { beef } & \text { bacon } & \text { chicken/poultry } & \text { lamb } \\ \text { ham } & \text { pork } & \text { sausages } & \text { liver/pâté } \\ \text { beefburger/hamburger } & \text { kidney } & \text { never eat meat } & \end{array}$

2. Which types of fish do you eat about once a week or more often? (you can cross more than one box)

$\begin{array}{lllll}\text { tuna } & \text { sardines } & \text { trout } & \text { 'fish \& chips' } & \text { salmon } \\ \text { other seafood } & \text { cod/haddock } & \text { mackerel } & \text { never eat fish } & \end{array}$

3. About how many times each week do you eat:

(please count all meals and snacks; put 'O' if less than once a week)

meat? _ number of times eaten each week (remember meat in sandwiches)

fish/seafood?___ number of times eaten each week

chips? _ _ number of times eaten each week

potatoes? _ _ number of times eaten each week

pasta? _ _ number of times eaten each week

rice? _ _ number of times eaten each week

cheese? _ _ number of times eaten each week (remember cheese in pizzas, quiches, cheese sauce, etc.)

4. About how many eggs do you eat each week?

number of eggs eaten each week (remember eggs in omelettes, quiches, cakes, etc.)

5. Which types of vegetables/salads (fresh, frozen or tinned) do you eat once a week or more often? (you can cross more than one box)

$\begin{array}{lllll}\text { green peas } & \text { tomatoes } & \text { green beans } & \text { broccoli } & \text { onions } \\ \text { cabbage } & \text { garlic } & \text { soya meat/tofu } & \text { carrots } & \text { swede } \\ \text { courgettes } & \text { spinach } & \text { cauliflower } & \text { beetroot } & \text { sweet corn } \\ \text { leeks } & \text { avocado } & \text { Brussels sprouts } & \text { parsnip } & \text { aubergine } \\ \text { lettuce } & \text { celery } & \text { cucumber } & \text { baked beans } & \text { mushrooms }\end{array}$

chick peas/lentils green/red peppers

6. About how much do you eat each week of:

(put ' $O$ ' if less than one)

cooked vegetables? number of heaped tablespoons each week

salad items/raw vegetables? number of heaped tablespoons each week (please count lettuce, tomato, etc. in sandwiches)

7. Which types of fruit do you eat once a week or more often, when in season? (you can cross more than one box)

apples bananas oranges, satsumas, etc.

grapefruit pears stone fruit (peaches, plums, nectarines, etc.) 
8. About how much fruit or fruit juice do you eat or drink each week?

(count 10 grapes, berries or raisins as one piece; put 'O' if less than one a week)

number of pieces of fresh fruit eaten each week

number of pieces of dried fruit eaten each week

number of glasses of fruit juice each week

number of tablespoons of stewed or tinned fruit eaten each week

9. About how many of the following do you eat?

(put ' $O$ ' if less than one)

number of slices/pieces of white bread each week

number of slices/pieces of brown/wholemeal bread each week

number of crackers, crispbread, etc. each week

number of sweet biscuits each week

number of dairy desserts (yoghurts, etc.) each week

number of cakes, puddings, pies, buns, etc. each week

approximate number of pieces of chocolate (in any food or drink) each week

number of boiled sweets/peppermints etc. each week

number of tablespoons of nuts (including peanut butter) each week

number of tablespoons of gravy, cream/cheese sauces, etc. each week

number of tablespoons of jam/marmalade each week

number of bowls of breakast-type cereal each week

If you eat breakfast cereal is it usually: $\begin{array}{lll}\text { bran cereal? (All-Bran, Bran Flakes, etc.) } & \text { muesli? } & \text { biscuit cereal? (Weetabix, Shreddies, etc.) } \\ \text { oat cereal? (porridge, Ready Brek, etc.) } & \text { other? }\end{array}$

10. Which type of spread do you use on bread, crispbread, etc., once a week or more often? (you can cross more than one box)

butter margarine soft cheese low-fat spread mayonnaise

salad cream olive oil spread Marmite, etc. rarely use spread

Do you spread it:

(please cross)

thick? medium? thin?

Do you add butter, etc. to:

potatoes?

other vegetables?

11. Which types of fats or oils do you use for cooking or salad dressing once a week or more often? (you can cross more than one box)

$\begin{array}{llll}\text { butter } & \text { soft (tub) margarine } & \text { White Flora } & \text { olive oil } \\ \text { hard (block) margarine } & \text { lard/dripping } & \text { corn oil } & \text { sunflower oil } \\ \text { mayonnaise } & \text { soya oil } & \text { other vegetable oil } & \text { salad cream }\end{array}$

Please put a cross in the box if you RARELY OR NEVER:

use fats or oils for cooking use salad dressing/cream 
12. Please put a cross in the box if you NEVER eat:

$\begin{array}{llll}\text { beef } & \text { pork/ham } & \text { lamb } & \text { dairy products } \\ \text { kidney } & \text { liver/pâté } & \text { sugar } & \text { wheat products } \\ \text { salami } & \text { sausages } & \text { eggs } & \text { beefburgers }\end{array}$

13. Which type of milk or cream do you drink or use once a week or more often? (you can cross more than one box)

$\begin{array}{llll}\text { full-cream } & \text { semi-skimmed } & \text { skimmed/fat-free } & \text { soya milk } \\ \text { single cream } & \text { double cream } & \text { dairy ice cream } & \text { never have milk/cream }\end{array}$

14. Do you never/sometimes/usually/always:

add milk to your tea? milk to your coffee? add salt to your food?

remove fat from meat? eat breakfast? eat an afternoon snack?

eat organic food?

15. Have you made any major changes to your diet in the last 5 years?

No Yes - because of illness Yes - for some other reason

16. About how much alcohol do you drink each week?

(one drink = a glass of wine, half pint of lager or tot of spirits; put 'O' if you drink less than one drink each week) number of drinks of alcohol each week

If you have more than one drink of alcohol each week:

is it usually with meals? no/yes/it varies

on how many days each week days each week do you usually drink?

17. About how much do you drink EACH DAY of:
cups of _ ${ }_{\text {fizzy/soft drink? }}^{\text {tizz }}$ ${ }_{\text {fizzy/soft drink? }}^{\text {tea? }}$ milk, hot chocolate, etc.? coffee? glasses of water? fruit squash?

18. How many teaspoons of sugar do you add to tea, coffee, cereal, fruit, etc. EACH DAY? number of teaspoons of sugar each day 